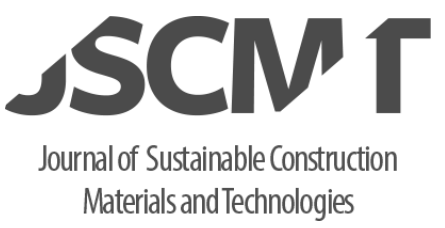

J Sustain. Construct. Mater. Technol. 4(1) (2019) 306-317
Journal of Sustainable Construction Materials and Technologies

www.eds.yildiz.edu.tr/jscmt

\title{
Thermomechanical Characterization of Particleboards from Powder Typha Leaves.
}

\author{
Younouss Dieye $^{\mathrm{a}, *}$, Pape M. Toure ${ }^{\mathrm{a}}$, Prince. M. Gueye ${ }^{\mathrm{a}}$, Vincent Sambou ${ }^{\mathrm{a}}$, Seckou Bodian ${ }^{\mathrm{a}}$, \\ Soumaila Tigampo ${ }^{\mathrm{a}}$
}

a Laboratoire d'Energétique Appliquée (LEA), Université Cheikh Anta Diop, BP:5085 Dakar-Fann, Sénégal

Manuscript Received December 12, 2018; Accepted February 18, 2019

\begin{abstract}
New composite boards with low-thermal conductivity produced from a mixture of powder Typha leaves and a binder as gum arabic have been developed. The goal of this paper was to investigate the effect of binder content on compressive strength and thermal properties of typha panels. The results showed that the panels with a binder content of $33.33-50 \%$ had the thermal conductivity values ranging from 0.055 to $0.083 \mathrm{~W} . \mathrm{m}^{-1} . \mathrm{K}^{-1}$, which was close to that of many natural insulating materials. The compressive strength values obtained were comparable to those of the lime - hemp concrete. This study showed that typha possesses interesting capacities of insulating and its combination with gum arabic contributes to the improvement of thermal comfort, to the reduction of the energy consumption as well as to the emissions of $\mathrm{CO}_{2}$.
\end{abstract}

Keywords: Typha; gum arabic; compressive strength; thermal conductivity; thermal effusity

\section{Introduction}

The building sector including the construction remains one of the major concerns of developing countries. Heating and cooling in buildings and industry account for about $40 \%$ of the world's energy consumption, according to the International Energy Agency (IEA), 70\% of which comes from fossil fuels. In Senegal 65\% of the energy consumption in the industrial sector comes from cement plants according to the Energy Information System of Senegal. From the point of view of $\mathrm{CO}_{2}$ emissions, the building sector remains one of the main sectors transmitters greenhouse gases. Saving energy is an important issue because of economic and environmental concerns. On this point to contribute to the requirements of COP21 to reduce $\mathrm{CO}_{2}$ emissions, the use of thermal insulation is regarded

${ }^{*}$ Corresponding author. Tel.: : +221 772540680

E-mail address: younouss.dieye@ucad.edu.sn (Y.Dieye)

https://doi.org/10.29187/jscmt.2019.34 
as one of the most efficient energy improvements in buildings and means of energy conservation in buildings. As the largest building component, the thermal insulation materials play an important role in achieving buildings' energy efficiency [1]. In construction, crude oil is the main source of raw material used in the production of synthetic insulatings (polystyrene, polyurethane, glass and rock wool etc.), which are widely used in thermal insulation of building structures [2], [3], [4]. However, the construction market is still dominated by synthetic insulating materials. Thermal insulating materials available in the local market are relatively expensive and until now are narrowly used by local contractors and small-size entrepreneurs [5]. Most synthetic insulation comes from non-renewable resources, expensive ones and their manufacturing process requires a lot of energy. To contribute to the reduction of energy consumption and the protection of the environment, it is therefore necessary to find new materials based on vegetable fibers which can substitute for conventional non-renewable reinforcing materials [6]. A great advantage of the insulation based on natural fibres is not only a low value of thermal conductivity but also the natural character of input fibres. Natural materials are easy to renew, locally available, their use for the production of construction materials greatly reduces the energy demands and are easily recycling and are lower cost [7], [8]. Several studies have been carried out on the use of vegetal fibers as thermal insulation materials [9]. The molding conditions, i.e. binder type and binder content, have an important influence on board density, mechanical and heat insulation properties. Chikhi et al. [10] investigated the effect of date palm fibers (DPF) on thermal conductivity, water absorption and mechanical properties of gypsum based materials. It was concluded that this new kind of bio-composite exhibits good thermal and mechanical performances which allow it to be applied as thermal insulation materials. S. Tangjuank [11] studies the properties of thermal insulation produced from pineapple leaves using natural rubber latex as a binder. He obtained a thermal conductivity of $0.035 \mathrm{~W} . \mathrm{m}^{-}$ ${ }^{1} . \mathrm{K}^{-1}$ for density of $210 \mathrm{~kg} / \mathrm{m}^{3}$. Agoudjil et al. [12] carried out an experimental investigation on the thermophysical, chemical and dielectric properties of three varieties of date palm wood and was confirmed that the date palm wood is a good candidate for the development of efficient and safe insulating materials. This study deals with the use of Typha australis fibers to make a building material gum arabic binder. R. K. Bozabe et al. [13] studied the valorization of the use of gum arabic as a binder by substituting cement for the manufacture of micro-concrete tiles. They showed that compared to the cement, rubber has interesting characteristics; it improves the tensile and bending strength of tiles. Typha or narrow-leaved cattail is a marginal weed which is occured in tropical area [14].Cattails rapidly spread via seeds and roots. In very short time it takes over water areas. It is usual to see ponds that are completely surrounded by cattails. It spreads rapidly over the areas and affecting other crops. So, abundant amount of it forced one to find its usefulness in insulation applications [15]. Luamkanchanaphan et al. [13] studied study physical, mechanical and thermal properties of insulation boards prepared from narrow-leaved cattail fibers by using Methylene Diphenyl Diisocyanate (MDI) as a binder. Their test results showed that the insulation boards had good physical and mechanical properties and thermal conductivity values of the board with a density of 200$400 \mathrm{~kg} / \mathrm{m}^{3}$ were less than that of fibrous materials and cellular materials. Diatta et al [16] showed in their study that the addition of typha fiber on concrete has improved its thermal properties. Ponnukrishnan et al. [17] studied the mechanical characterization of Tyhpa Domingensis natural fiber which reinforced polyester composites and they showed that the increase in the volume fraction of fiber decreases the density of the panels and increases the tensile strengthThe scope of the paper is to valorize a $100 \%$ vegetable insulation material based on typha australis leaves powder and a binder in gum arabic to reduce the energy consumption in the building. In this order, the influence of binder content on mechanical and thermal properties of panels with and without humidity were studied. Compressive strength, thermal conductivity and thermal effusivity are examined.

\section{Experiment}

The test panels were made with powder obtained from powder Typha leaves and gum arabic as binding material.

\subsection{Materials}


The binder used here is gum arabic Figure 1. Gum arabic comes from a tree called acacia and is available in the market as crystals or powders. The density of gum arabic was $515 \mathrm{~kg} . \mathrm{m}^{-3}$. The moisture content of gum Arabic was $16.5 \%$. Crystals of gum arabic were immersed for a few days in water before being mixed to obtain a viscous liquid that sticks. The mass ratio between the binder and water $(\mathrm{G} / \mathrm{E})$ was taken to be 1: 2 .

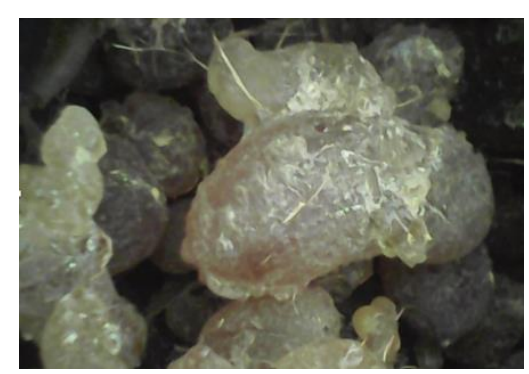

Figure 1. Gum arabic crystals

The leaves of typha australis used were extracted in the zone of Niayes in Dakar. They were dried under the sun for three weeks before being cut into small pieces. After cutting, the sheets were thus transformed into powder by a disk mill (Figure 2). The results of the granulometric analysis of the Typha used are illustrated in Figure 3. The density of typha material was $128.4 \mathrm{~kg} \cdot \mathrm{m}^{-3}$. The average moisture content of typha material determined by weighing of typha sample before and after drying for $24 \mathrm{~h}$ at $105^{\circ} \mathrm{C}$ was found $12.24 \%$.

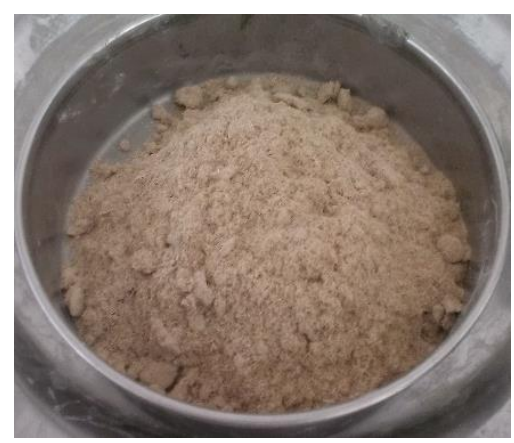

Figure 2. Typha leaves powder

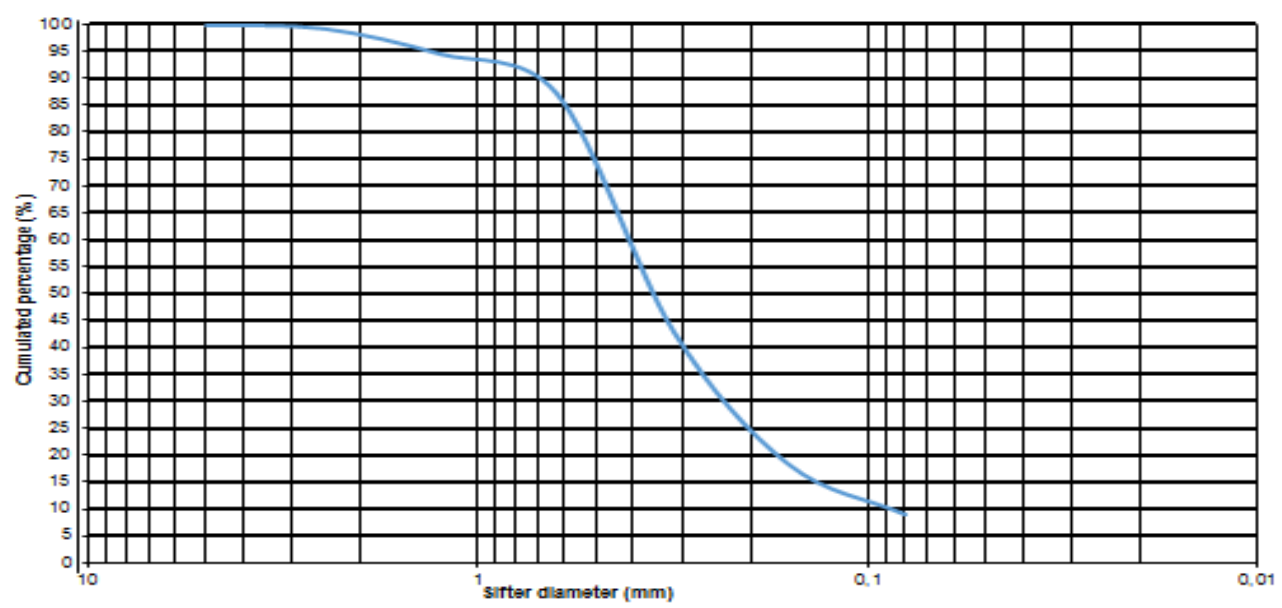

Figure 3. Granulometric graph of typha used 


\subsection{Preperation of samples}

Experimental mixture consisted of powder of typha leaf, of binder of gum arabic and water. Samples were made by mixing typha material with the binder material in the beater during $5 \mathrm{~min}$. The mixture was malaxated using a mixer type E095. The mixer had specific speed of 62 and a capacity of $5 \mathrm{~L}$. The mass composition of the different samples is given in Table 1. For the mechanical tests, a mould of dimensions $4 \mathrm{~cm} \times 4 \mathrm{~cm} \times 16 \mathrm{~cm}$ was used to prepare samples and the thermal test samples were also prepared in a mould of dimensions $10 \mathrm{~cm} \times 10 \mathrm{~cm} \times 2 \mathrm{~cm}$. The material obtained was poured in the moulds and tamped. The specimens were cured for one day in an indoor climate and then removed from the forms. Curing was continued under the air during 15 days.

Table 1. Masses of the different compounds

\begin{tabular}{ccccc}
\hline Samples & Binder percentage $(\%)$ & Binder mass $(\mathrm{g})$ & Typha leaves powder mass $(\mathrm{g})$ & Water mass $(\mathrm{g})$ \\
\hline $\boldsymbol{E}_{\mathbf{1}}$ & 33.33 & 48 & 96 & \\
$\boldsymbol{E}$ & 38.23 & 52 & 72 & 104 \\
$\boldsymbol{E}_{\mathbf{3}}$ & 47.46 & 56 & 72 & 112 \\
$\boldsymbol{E}_{\mathbf{4}}$ & 50 & 60 & 60 & 120 \\
\hline
\end{tabular}

\subsection{Testing methods}

Density, compressive strength, thermal conductivity and thermal effusivity were measured on dried specimens in the air.

\subsubsection{Physical test}

We determined the density and moisture content of the materials. Bulk density was determined using a $0.01 \mathrm{~g}$ precision scale for weighing and $0.01 \mathrm{~mm}$ precision calipers to measure sample sizes. For each composition, 5 measurements were made, in order to obtain an average. The moisture content of the typha material was determined by weighing the samples before and after drying for 24 hours at $105^{\circ} \mathrm{C}$.

\subsubsection{Mechanical tests}

The mechanical tests were performed on the specimens. The compression tests were performed using the universal testing machine. This characterization was done by using an E0160 type mechanical press with a maximum force of $250 \mathrm{kN}$. The specific speed of the force application was $2 \mathrm{kN} / \mathrm{sec}$. For compression tests, the specimens were placed as described in Figure 4. 


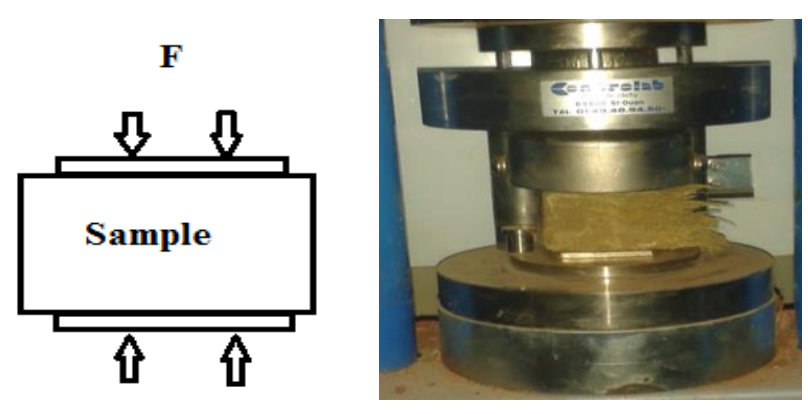

Figure 4. Compression Test

A compressive strength test was performed in which four specimens per mix were tested. The specimens were compressed with forces as well as relative displacements measured. Stress, $\sigma$ in MPa, was calculated using Eq.(1)

$$
\sigma=\frac{F}{S}
$$

$\mathrm{S}$ is the sample section in $\mathrm{mm}^{2} ; \mathrm{F}$ is the force applied (N)

\subsubsection{Thermal test}

All thermophysical experiments were performed using samples of dimensions $100 \mathrm{~mm} \times 100 \mathrm{~mm} \times 10 \mathrm{~mm}$. The thermal conductivity and effusivity of samples were determined simultaneously using a transient method [18], [19]. The method used is the hot plate transient method. The different elements that make up the experimental device represented in Figure 5 are as follows. The hot plate method was then used in an asymmetrical configuration. It consists in embedding a heating element on which a thermocouple was fixed, between the material to be characterized and a $5 \mathrm{~cm}$ thick polystyrene plate. The whole set was put between two aluminum blocks with a thickness $4 \mathrm{~cm}$. A flux step is sent in the heating element and the temperatures $T_{s}(t)$ at the center of the heating element is recorded. The processing of the recording of $\mathrm{T}_{\mathrm{S}}(\mathrm{t})$ is realized by supposing that the heat transfer at the center of the heating element is $1 \mathrm{D}$. The temperature at the level of the aluminum block is constant.

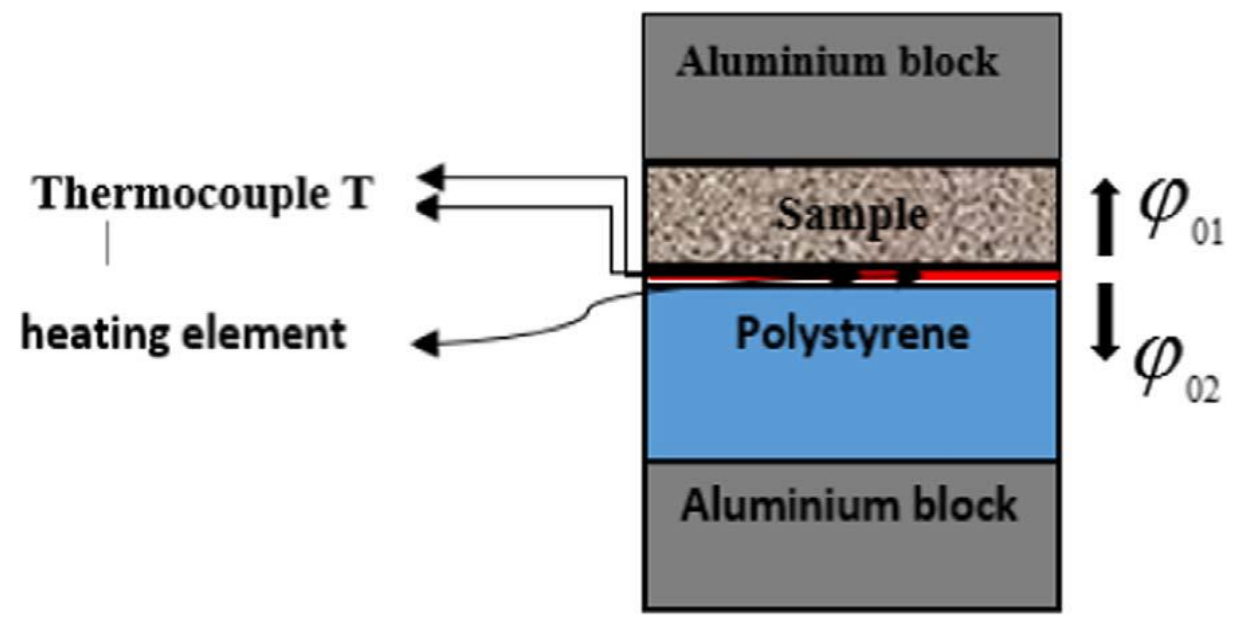

Figure 5. schema of the experimental asymmetrical hot plate device

In this case, the thermal quadrupole method [20] can be used to solve the thermal transfer problem. Indeed, in Laplace's space, the heat equation no longer depends on the space variable. This method makes it possible then to relate the input and output flows and temperatures using a passing matrix. 


$$
\begin{aligned}
& {\left[\begin{array}{l}
\theta_{s} \\
\phi_{01}
\end{array}\right]=\left[\begin{array}{cc}
1 & 0 \\
C s S p & 1
\end{array}\right]\left[\begin{array}{cc}
1 & R_{C} \\
0 & 1
\end{array}\right]\left[\begin{array}{cc}
A & B \\
C & D
\end{array}\right]\left[\begin{array}{c}
0 \\
\phi_{1}
\end{array}\right]\left[\begin{array}{ll}
A_{1} & B_{1} \\
C_{1} & D_{1}
\end{array}\right]=\left[\begin{array}{l}
0 \\
\phi_{1}
\end{array}\right]} \\
& {\left[\begin{array}{c}
\theta_{s} \\
\phi_{02}
\end{array}\right]=\left[\begin{array}{cc}
A_{i} & B_{i} \\
C_{i} & D_{i}
\end{array}\right]\left[\begin{array}{c}
0 \\
\phi_{2}
\end{array}\right]}
\end{aligned}
$$

With:

$$
\begin{aligned}
& A=D=\cosh \left(\frac{E}{\lambda} \sqrt{p} e\right) ; B=\frac{\sinh \left(\frac{E}{\lambda} \sqrt{p} e\right)}{E S \sqrt{p}} ; C=E S \sqrt{p} \sinh \left(\frac{E}{\lambda} \sqrt{p} e\right) \\
& A_{i}=D_{i}=\cosh \left(\frac{E_{i}}{\lambda_{i}} \sqrt{p} e_{i}\right) ; B_{i}=\frac{\sinh \left(\frac{E_{i}}{\lambda_{i}} \sqrt{p} e_{i}\right)}{E_{i} S \sqrt{p}} ; C i=E_{i} S \sqrt{p} \sinh \left(\frac{E_{i}}{\lambda_{i}} \sqrt{p} e_{i}\right)
\end{aligned}
$$

$\lambda$ is the sample thermal conductivity; E the sample thermal effusivity; e the sample thickness; $\lambda_{\mathrm{i}}$ the polystyrene thermal conductivity; $\mathrm{E}_{\mathrm{i}}$ the polystyrene thermal effusivity; $\mathrm{e}_{\mathrm{i}}$ the polystyrene thickness; $\theta_{\mathrm{s}}$ the Laplace transform of the temperature $\mathrm{T}_{\mathrm{s}}(\mathrm{t}) ; C_{s}$ the thermal capacity of the heating element per area unit: $C_{s}=\rho_{s} c_{s} e_{s} ; R_{c}$ the thermal contact resistance between the heating element and the sample; $\phi_{1}$ the Laplace transform of heat flux input on the upper aluminum block; $\phi_{2}$ the Laplace transform of heat flux input on the lower aluminum block; $\phi_{01}$ the Laplace transform of the heat flux density living the heating element (upstream); $\phi_{02}$ the Laplace transform of the heat flux density living the heating element (downstream).

After developing the matrix products (2) and (3), the following relations were obtained:

$$
\begin{aligned}
& \phi_{01}=\theta_{s} \frac{D 1}{B 1} \\
& \phi_{02}=\theta_{s} \frac{D_{i}}{B_{i}}
\end{aligned}
$$

The total flow was:

$$
\begin{aligned}
& \phi_{0}=\phi_{01}+\phi_{02} \\
& \phi_{0}=\theta_{s}\left(\frac{D_{1}}{B_{1}}+\frac{D_{i}}{B_{i}}\right)
\end{aligned}
$$

Inferring $\theta_{s}$ from expression (7),

$$
\theta_{s}=\phi_{0} \frac{1}{\left(\frac{D_{1}}{B_{1}}+\frac{D_{i}}{B_{i}}\right)}
$$

was finally obtained.

The principle of the method is thus to estimate the values of the parameters $\lambda$ and eventually $\mathrm{E}$ which minimize 
the sum of the quadratic errors $\sum_{i=1}^{N}\left[\boldsymbol{T s}\left(\boldsymbol{t}_{i}\right)-\boldsymbol{T} \boldsymbol{s}_{\text {mod }}\left(\boldsymbol{t}_{i}\right)\right]$ between the experimental curve $\boldsymbol{T s}(\boldsymbol{t})=\boldsymbol{T s}(\mathbf{0}, \boldsymbol{t})$ and the theoretical curve $\boldsymbol{T} \boldsymbol{s}_{\text {mod }}(\boldsymbol{t})=\boldsymbol{T} \boldsymbol{s}_{\text {mod }}(\mathbf{0}, \boldsymbol{t})$ calculated with relation (8) supposing that the heat transfer remains $1 \mathrm{D}$ at the center of the heating element.

\section{Results and discussion}

\subsection{Mechanical results}

We first present the density before compressive strength.

\subsubsection{Density}

Bulk density was determined using a $0.01 \mathrm{~g}$ precision scale for weighing and $0.01 \mathrm{~mm}$ precision calipers to measure sample sizes. For each composition, 5 measurements were made, in order to obtain an average. Fig. 6 shows the variation of the density of typha panels according to the mass percentage of binder. The increase of the binder content in the formulation of typha panels obviously implies the increase of the density. We observe an increase in the density as a function of the binder content. The density varies respectively from $459 \mathrm{~kg} / \mathrm{m}^{3}$ to $500 \mathrm{~kg} / \mathrm{m}^{3}$ when the mass concentration of gum arabic varies from $33.33 \%$ to $50 \%$. These results are comparable to the hemp concrete [21] whose density varies from 250 to $660 \mathrm{~kg} / \mathrm{m}^{3}$ depending on the percentage of binder (10\% to $40 \%$ ). This can be explained by the fact that the binder has a higher density. This means that more than the quantity of binder increase more the material becomes dense, and the higher is the density.

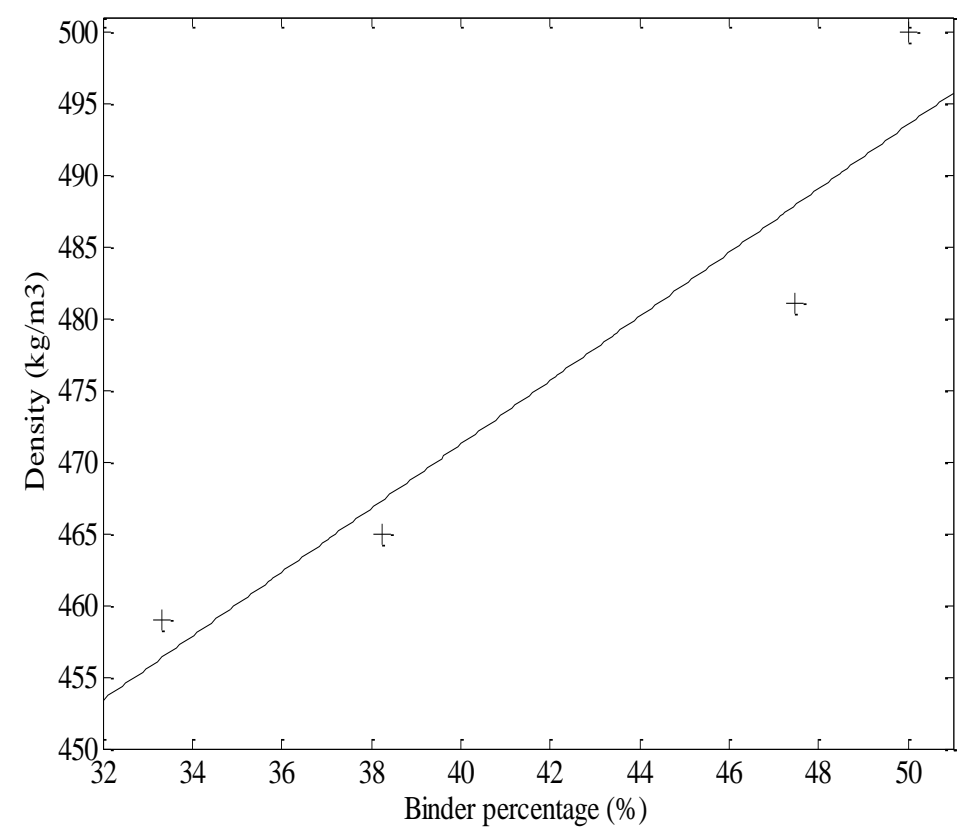

Figure 6. Variation curve of density in function of the binder percentage

\subsubsection{Compressive strength}

The mechanical results concerned the mechanical resistance to compression. As regards compressive strength of samples, these values ranged from 0.373 to $0.771 \mathrm{MPa}$ in function of the binder percentage. It was observed that 
mechanical strength increase in function of the binder content. This can be explained by the fact that more the dosage of binder is great, more the link of fibers is important, thus increasing their mechanical performance. The level of mechanical performance of the panels depends on the thickness of the layer of binder coating the particles. These results were comparable to those of the lime - hemp concrete [15] whose resistance to compression values vary from 0.15 to $0.83 \mathrm{MPa}$.

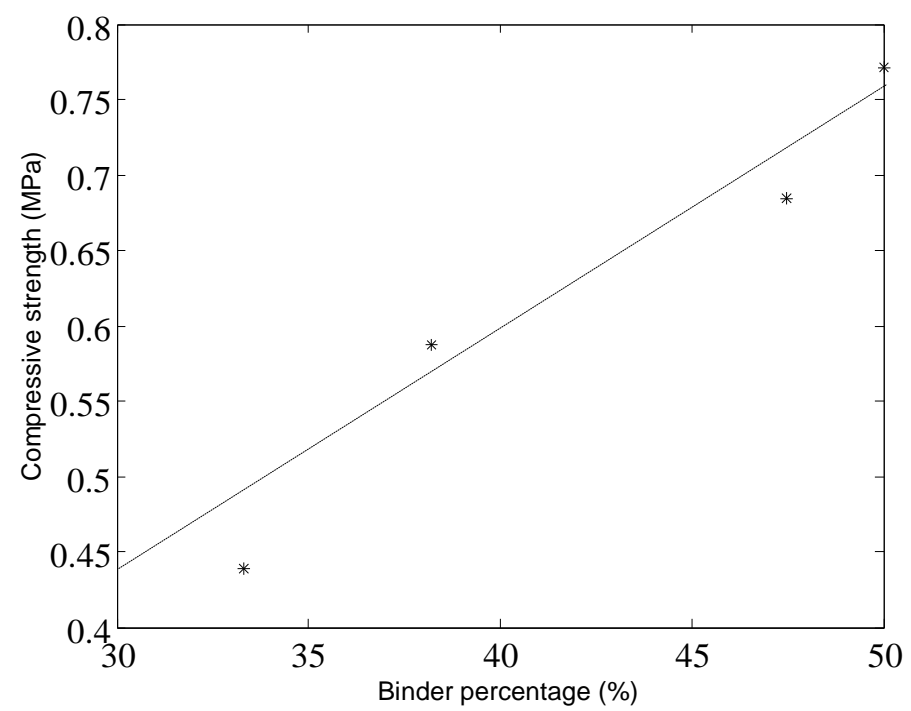

Figure 7. Variation curve of compressive strength in function of the binder percentage

\subsection{Thermal results}

We determined the thermal conductivity and thermal effusivity of panels of typha in function of binder content. First of all, we determined thermal conductivity and effusivity on samples dried in air and, subsequently, on driedup sample pieces. Figures. 8 and 9 shows the measured thermals conductivity and effusivity as function of binder content at dried status. The results show that increasing the binder content, causes an increase in thermal conductivity and thermal effusivity, respectively ranging from 0.055 to $0.083 \mathrm{~W} . \mathrm{m}^{-1} \cdot \mathrm{K}^{-1}$ and 173.76 to $219.45 \mathrm{~J} . \mathrm{m}^{-}$ ${ }^{2} .{ }^{\circ} \mathrm{C}^{-1} \cdot \mathrm{s}^{-1 / 2}$ for the dry panels. The thermal conductivity of the prepared materials is very promising and comparable with the commercial thermal insulators and building materials [8]. This values is close to the thermal conductivity range of many insulating materials such as wood-fiber insulation boards, used for thermal insulation in roofs, walls and floors. Likewise, the thermal conductivity values are close to or lower than many of natural insulating materials like: jute $\left(0.0482 \mathrm{~W} \cdot \mathrm{m}^{-1} \cdot \mathrm{K}^{-1}[22]\right)$, hemp $\left(0.06858 \mathrm{~W} \cdot \mathrm{m}^{-1} \cdot \mathrm{K}^{-1}[23]\right)$ and date palm fibers $\left(0.177 \mathrm{~W} \cdot \mathrm{m}^{-1} \cdot \mathrm{K}^{-1}[10]\right)$. The water content had a significant effect on the material properties. Figures. 10 and 11. shows the thermal properties of Typha materials with a moisture content. The moisture content of the typha material was determined by weighing the samples before and after drying for 24 hours at $105^{\circ} \mathrm{C}$.We observe that the values of the thermal conductivity of typha panels are significantly influenced by the water content. It is the fact that the materials that we have studied are porous. The water contained in the pores of the materials has a strong influence on the thermal properties. Being very conductive, it modifies the thermal conductivity of typha panels. For example, for the typhagum arabic board, with $33.33 \%$ binder, the water content leads to an increase in conductivity of $22 \%$ compared to the dry state. 


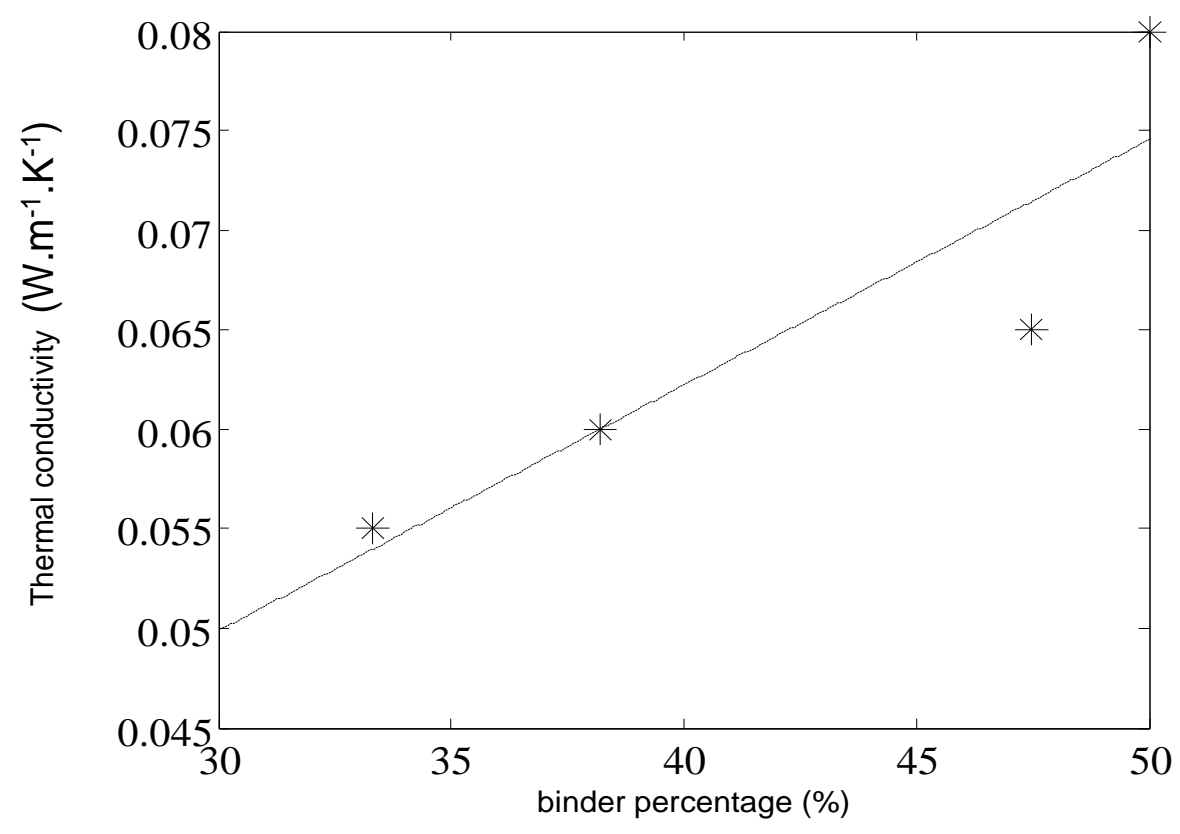

Figure 8. Dry panel thermal conductivity in function of the binder

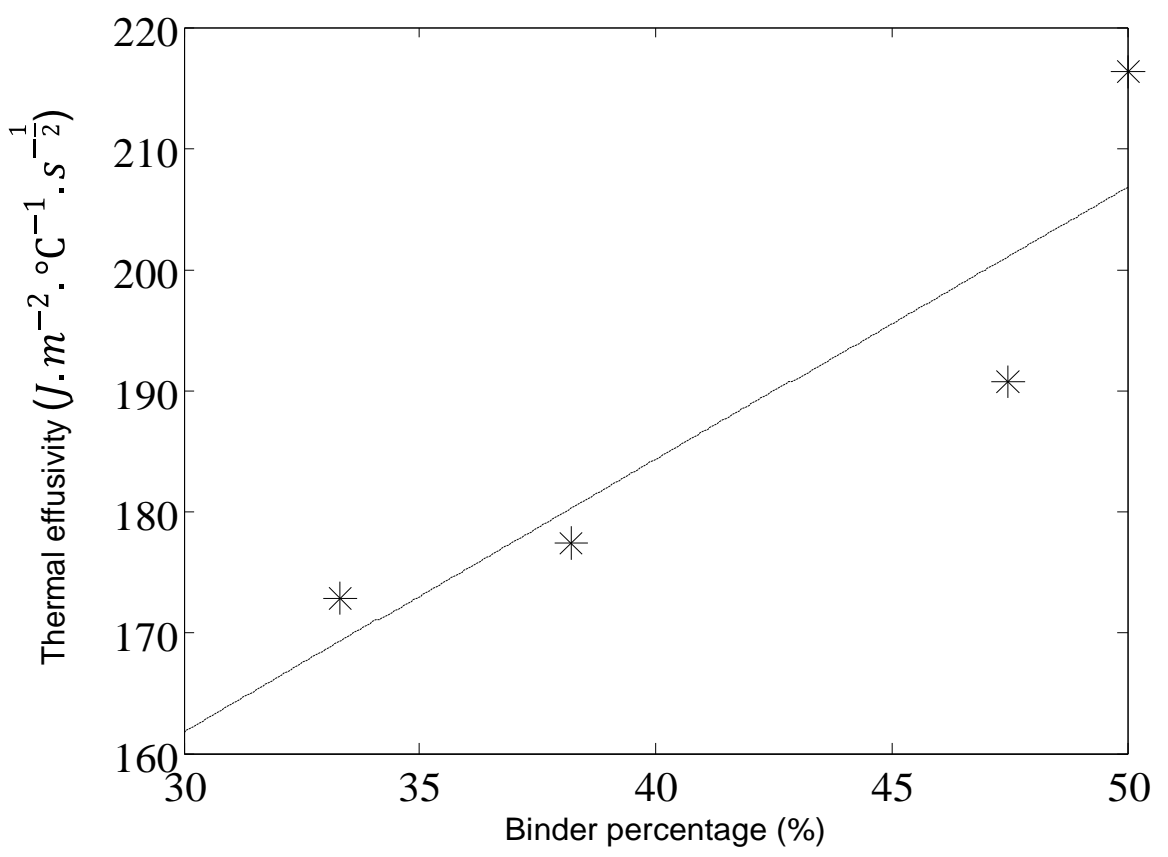

Figure 9. Dry panel thermal effusivity in function of the binder 


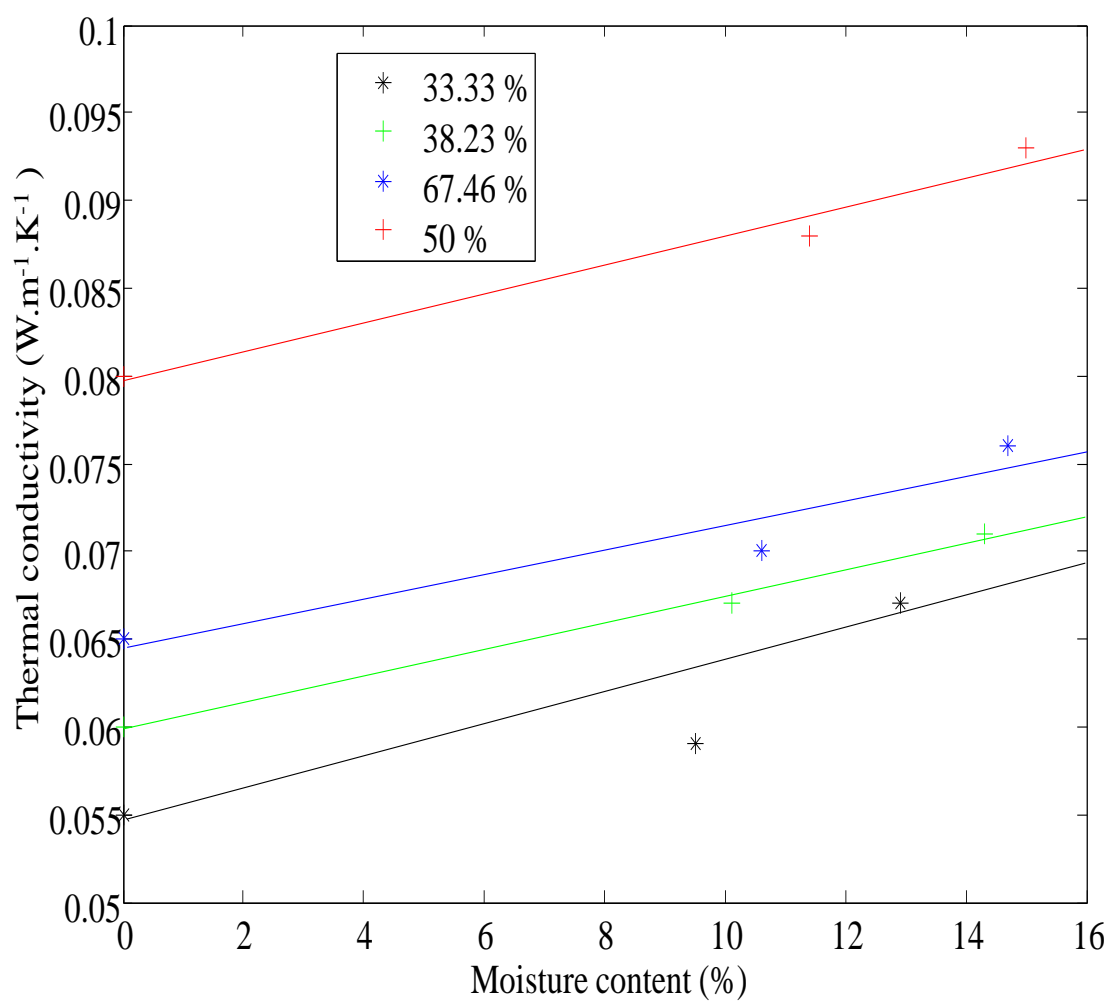

Figure 10. Thermal conductivity of Typha - gum arabic panels, depending on water content

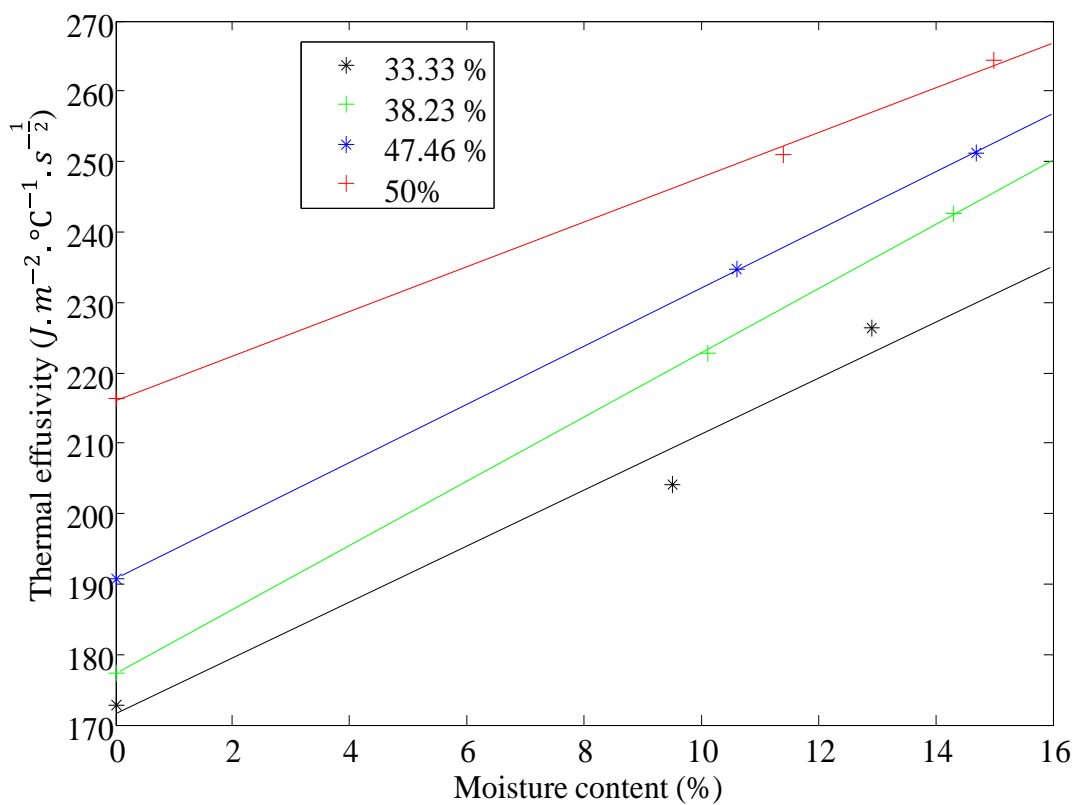

Figure 11. Thermal effusivity of Typha - gum arabic panels, depending on water content 


\section{Conclusion}

This paper reports the results of an experimental investigation on the thermophysical and mechanical properties of powder of typha leaves. The goal is to use this natural material in the manufacture of thermal insulation for buildings and only to evaluate the possibility of using the new biocomposite as insulating material to reduce the energetics comsumption in buildings.

As results, the compressive strength for whole biocomposites samples based on typha rise with the increasing of binder content. However, the compressive strength of these panels is not sufficient for the material to be load bearing.

From a thermal point of view, we obtained low conductivities. The samples obtained have a good thermal insulation capacity and are comparable to hemp concrete - starch. The panels have low thermal effusivities so that they have a low thermal inertia. The water sensitivity of the panels also has a major impact on the thermal properties of the panels.

\section{Acknowledgements}

We thank the Coordinator of Project of Thermal Insulation Material Production to based of Typha in Senegal (PNEEB / TYPHA) and the director of the Applied Energy Laboratory (LEA).

\section{References}

[1] Cabeza, L.F., Castell, A., Medrano, M., Martorell, I. (2010) Experimental study on the performance of insulation materials in Mediterranean construction. Energy and Buildings, 42, 630-636

[2] Jelle, B. P. (2011) Traditional, state-of-the-art and future thermal building insulation materials and solutions Properties, requirements and possibilities. Energy and Buildings, 43, 2549-2563

[3] Baetens, R., Jelle, B. P., Gustavsend, (2011) A. Aerogel insulation for building applications: A state-of-the-art review, Energy and Buildings, 43, 761-769

[4] Papadopoulos, A.M. (2005) State of the art in thermal insulation materials and aims for future developments. Energy and Buildings, 37, 77-86

[5] Tettey, U.Y.A., Dodoo, A., Gustavsson, L. (2014) Effects of the different insulation materials on primary energy and CO2 emission of a multi-storey residentiel buildings. Energy and Buildings, 82, 369-377.

[6] Zach, J., Hroudová, J., Brožovský, J., Krejzad Z. (2013) Development of Thermal Insulating Materials on Natural Base for Thermal Insulation Systems, Procedia Engineering, 57, 1288 - 1294

[7] Nguong, C. W., Lee, S. N. B., Sujan D. (2013) A Review on Natural Fibre Reinforced Polymer Composites, International Journal of Chemical, Nuclear. Metallurgical and Materials Engineering, 7, 33-40

[8] Canbolat, S.., Kut, D., Dayioglu, H., Merdan, N. (2013) Investigation of the effects of pumice stone powder and polyacrylic ester based material on thermal insulation of polypropylene fabrics. TEKSTIL ve KONFEKSIYON , 23, 4, 349-355

[9] Evon, P., Vinet J., Rigal, M., Labonne, L. (2015) New Insulation Fiberboards from Sun ower Cake With Improved Thermal and Mechanical Properties. Journal of Agricultural Studies, 3, 194-211.

[10] Chikhi, M., Agoudjil, B., Boudenne, A., Gherabli, A. (2013) Experimental investigation of new biocomposite with low cost forthermal insulation. Energy and Buildings, 66, 267-273

[11] Tangjuank, S. (2011) Thermal insulation and physical properties of particleboards from pineapple leaves. International Journal of Physical Sciences, 6, 4528-4532

[12] Agoudjil, B., Benchabane, A., Boudenne, A., Ibos, L. (2011) Renewable materials to reduce building heat loss: Characterization of date palm wood. Energy and Buildings, 43, 491-497

[13] BOZABE, R. K., TOUKOUROU, C. A. GBAGUIDI, G. A. et HOUNKONNOU, M. N. (2013) Étude des caractéristiques physico-mécaniques des tuiles en micro-béton fabriquées localement à base de la gomme arabique. Afrique Science, 09, $1-15$

[14] Luamkanchanaphan, T., Chotikaprakhan, S., Jarusombati, S. (2012) A study of physical, mechanical and thermal properties for thermal insulation from Narrow-leaved Cattail fibers. APCBEE Procedia, 1, 46-52.

[15] Bruijn, P. B., Jeppsson, K. H., Sandin, K., Nilson, C. (2009) Mechanical properties of lime- hemp concrete containing shives and fibres, Biosystems Engineering, 103, 474-479 
[16] Diatta, M., Gaye, S., Thiam, A., Azilinon, D. (2011) Détermination des propriétés thermophysique et mécanique du typha australis. Congres SFT, Perpignan, (France).

[17] Ponnukrishnan, P., Chithambara, T. M., Richard, S. (2013) Mechanical characterization ot typha domingensis natural fiber reinforced polyester composites. American International Journal of Research in Science, Technology, Engineering \& Mathematics, 241-244

[18] Bal, H., Jannot, Y., Quenette, N., Chenu, A. (2012) Water content dependence of the porosity, density and thermal capacity of laterite based bricks with millet waste additive. Construction and Buildings Materials, 31, 144150.

[19] Jannot, Y., Felix, V., Degiovanni, A. (2010) A centered hot plate method for measurement of thermal properties of thin insulating materials. Measurement Science And Technology, 21, 1-8.

[20] Mailllet, D., Andre, S., Batsale, J.C. (2000) Thermal Quadrupoles: Solving the heat equation through integral transforms. Wiley, New York,

[21] Cerezo, V. (2005) Propriétés mécaniques, thermiques et acoustiques d'un matériau à base de particules végétales: approche expérimentale et modélisation théorique. These de l'Ecole Nationale des Travaux Publics de l'Etat,

[22] Zach J., Brožovský, J., Hroudová, J. (2010) Research and development of thermal-insulating materials. The $10^{\text {th }}$ International Conference, Modern Building Materials, Structures and Techniques, 330-334.

[23] Cigasova, J., Stevulova, N., Sicakova, A., Junak, J. (2013) Some aspects of lightweight composites durability. Chemical Engeenring Transactions, 32, 1615-1620 